\title{
Geociências no Ensino Médio Brasileiro - Análise dos Parâmetros Curriculares Nacionais
}

\author{
Maria Cristina Motta de Toledo (mcristol@usp.br) \\ Departamento de Geologia Sedimentar e Ambiental - Instituto de Geociências - USP \\ R. do Lago 562, CEP 05508-080, São Paulo, SP, BRA \\ Recebido em 11 de julho de 2003; aceito em 29 de abril de 2004
}

Palavras-chave: educação, Geociências, Geologia, Parâmetros Curriculares Nacionais.

\section{RESUMO}

A análise dos Parâmetros Curriculares Nacionais para o Ensino Médio (PCNEM), no tocante aos conteúdos em Geociências, mostra que estes são considerados importantes, sendo mencionados em disciplinas específicas (Biologia, Química, Física e Geografia) e na parte interdisciplinar (Brasil, 1999). Os PCNEM consideram condição de cidadania, e não prerrogativa de especialistas, o saber matemático, científico e tecnológico, nos quais são incluídos vários temas das Geociências, notadamente da Geologia. Com as pesquisas atuais sobre as mudanças ambientais globais e locais, fruto das atividades humanas integradas aos ciclos naturais, fica claro que o ensino útil à vida e ao trabalho preconizado pelos PCNEM deve incluir o conhecimento integral sobre o funcionamento do ambiente e das relações de interdependência de todos os seus setores, inclusive a biosfera, numa perspectiva histórica da evolução planetária. No entanto, no Brasil, salvo raras exceções, os tópicos geocientíficos têm tido um tratamento fragmentado e disperso, insuficiente para promover a compreensão da Terra como um sistema complexo e dinâmico, e para desenvolver a sensibilidade necessária para enfrentar os desafios impostos pela degradação ambiental, mostrando um caráter antropocêntrico e imediatista da filosofia de orientação dos conteúdos. Este trabalho procura demonstrar que, para atingir os objetivos da educação básica, (Brasil, 1996, 1999), é preciso incluir um tratamento abrangente dos conhecimentos em Ciências da Terra, integrados às outras Ciências da Natureza e com a Geografia. O trabalho conclui que o estudo global da natureza em sua totalidade complexa pode contribuir de forma significativa ao alcance dos objetivos da educação.

Keywords: education, Geosciences, Geology, Brazilian National Curricular Parameters.

\begin{abstract}
Analysis of the Brazilian National Curricular Parameters for Middle-Level Education (NCPME) reveals that subject matter in the Geosciences is considered important both in specific courses (Biology, Chemistry, Physics and Geography) and in interdisciplinary subjects. The NCPME consider mathematical, scientific and technological knowledge, including various themes in the Geosciences, most notably Geology, as necessary for the average citizen and not just the prerogative of specialists. With recent developments in research on local and global environmental changes as the result of man's interaction with natural cycles, it has became clear that the type of education commended as useful for life and employment in the NCPME should attempt to integrate knowledge as to the functioning of the environment and the interdependency of all its sectors, including the Biosphere, within the historical perspective of planetary evolution. Except in rare instances, however, geoscientific topics in Brazil, have traditionally been treated in a fragmented, dispersed way, revealing the anthropocentric and short-sighted nature of the philosophy orienting subject matter. This has proved insufficient not only for promoting comprehension of the Earth as a complex and dynamic system but also for developing the sensitivity necessary to confront the present challenges imposed by environmental degradation. This paper demonstrates that in order to accomplish the objectives of Basic Education in Brazil it will be necessary to include a broad treatment of geoscientific knowledge integrated with the other natural sciences and with Geography. It is concluded that the holistic study of nature, in all its complexity, can contribute significantly to reaching the fundamental goals of education.
\end{abstract}




\section{INTRODUÇÃO}

A Lei de Diretrizes e Bases da Educação Nacional (LDBEN) (Brasil, 1996), promulgada em 20 de dezembro de 1996, estabelece como finalidade da educação "o pleno desenvolvimento do educando, seu preparo para o exercício da cidadania e sua qualificação para o trabalho" (Art. 2). Como finalidades do ensino médio, estabelece "a consolidação e o aprofundamento dos conhecimentos", "a preparação básica para o trabalho e a cidadania”, "o aprimoramento como pessoa humana, incluindo a formação ética e o desenvolvimento da autonomia intelectual e do pensamento crítico" e "a compreensão dos fundamentos científico-tecnológicos dos processos produtivos" (Art. 35).

Os Parâmetros Curriculares Nacionais para o Ensino Médio (PCNEM) (Brasil, 1999), ao difundirem os princípios estabelecidos na LDBEN e ao orientarem o professor na busca do alcance dos objetivos desta etapa da educação básica, mostram intenções admiráveis para a Educação, em todos os âmbitos, e sua aplicação real representará um ganho enorme de qualidade na educação da população brasileira, dando significado ao conhecimento escolar, contextualizando os conhecimentos e valorizando a interdisciplinaridade, segundo síntese de seus objetivos.

A universalização da educação básica é defendida, considerando o "desenvolvimento do saber matemático, científico e tecnológico" uma "condição de cidadania e não prerrogativa de especialistas”. Na parte referente às Bases Legais e na descrição da área Ciências da Natureza, Matemática e suas Tecnologias, são mencionados objetivos referentes à necessidade de prover os estudantes da compreensão da dinâmica natural, e, no que se refere a temas de Geologia, o "funcionamento natural do planeta", a "evolução da atmosfera permitindo a manutenção da vida", a "história geológica da vida", a "percepção evolutiva da vida, do planeta e do cosmos", a "compreensão das alterações na atmosfera, hidrosfera, biosfera e litosfera pelas atividades humanas", entre outros, são mencionados como temas necessários na educação. Além disso, a educação deve "prover um ensino útil à vida e ao trabalho, no qual as informações, o conhecimento, as competências, as habilidades e os valores desenvolvidos sejam instrumentos reais de percepção, satisfação, interpretação, julgamento, atuação, desenvolvimento pessoal ou de aprendizado permanente", ou seja, formando cidadãos capazes de compreender o mundo e atuar na sociedade com consciência e responsabilidade, fazendo julgamentos e opções adequadas no âmbito da sustentabilidade (citações de Brasil, 1999).

No entanto, considera-se, nos PCNEM, que temas de Geociências devem ser tratados de forma interdisciplinar nas várias disciplinas. Assim, tanto em Biologia, como em Química e, menos, em Física, há referências a temas geocientíficos. Em Biologia, o texto chega a indicar a história geológica da vida como tema que deve ser desenvolvido. Em Química, há toda uma série de citações de tópicos de Geoquímica como necessários ao conhecimento do educando.

A Geografia, disciplina onde tradicionalmente são tratados vários conteúdos das Ciências da Terra, é reconhecida, no texto dos PCNEM, como estando a meio caminho entre as Ciências Humanas e as Ciências Naturais, muito embora tenha já sido redefinida como Ciência Social. Não obstante, vários objetivos a serem atingidos no estudo da Geografia preconizado pelos PCNEM apontam para o estudo concreto da natureza e das paisagens ocupadas pela sociedade. A própria evolução da sociedade humana, tratada tanto pela História como pela Geografia, teve suas etapas batizadas com expressões alusivas à utilização dos recursos minerais: idade da pedra lascada, idade da pedra polida, idade dos metais, era industrial (transformação dos recursos naturais).

Por entender que as Geociências têm uma grande contribuição a fazer no caminho rumo aos objetivos do ensino médio expostos nos PCNEM e, num âmbito mais geral, para o alcance da sustentabilidade, foi preparada esta análise. Nela, são destacadas várias menções dos textos dos PCNEM, nas partes que visam a contribuir para o processo de elaboração e de desenvolvimento dos projetos educativos das escolas, tanto no âmbito geral como nas áreas de conhecimentos específicos, quando fazem alusão a temas geocientíficos, à interdisciplinaridade, à sustentabilidade e ao exercício da cidadania, evidenciando o papel que uma Ciência integradora de conceitos de várias áreas como a Geologia (ou, de uma forma mais abrangente ainda, as Geociências) pode desempenhar na educação básica.

A discussão sobre a classificação e hierarquização de todas as Ciências ou campos do conhecimento que abordam o planeta é uma questão complexa e polêmica, que não é o objetivo deste trabalho. Cabe destacar que o termo Geociências é aqui utilizado como o conjunto das Ciências que estudam a Terra, seus vários compartimentos, materiais e processos e, principalmente, sua evolução histórica, desde a origem do Sistema Solar, e até mesmo a comparação com outros corpos do sistema solar ou fora dele. Na classificação usual em agências financiadoras de pesquisas, Geociências incluem Geologia, Geofísica, Meteorologia, Geodésia e Geografia Física. Em nosso contexto, devemos ainda considerar a Oceanografia, além de outras ora consideradas Ciências independentes, ora consideradas ramos da Geologia ou da Geografia Física, que contribuem para a compreensão do Sistema Terra.

A Geologia aparece muitas vezes destacada deste conjunto por vários motivos, principalmente por ser considerada uma Ciência histórica da natureza, segundo concepção de Potapova (1968) e Frodeman (1995), prestando-se muito bem a um papel fundamental no alcance dos objetivos da 
educação, por abranger e articular todos os aspectos da dinâmica da Terra. Além disso, os temas mencionados nos PCNEM são essencialmente temas geológicos, envolvendo Geoquímica, Sedimentologia, Paleontologia, Mineralogia, Recursos Naturais, entre outros, além de campos normalmente associados à Geografia Física, cujos objetos de estudo têm sua origem e evolução ligadas aos processos geológicos, como Pedologia e Geomorfologia.

\section{IMPORTÂNCIA DO ESTUDO DA TERRA NA EDUCAÇÃO ESCOLAR}

Desde que o curso de História Natural foi extinto, em 1970, seus conteúdos em Geociências passaram a ser ministrados apenas nos cursos de Geologia, que foram criados em 1963 visando à formação de profissionais para o mapeamento geológico básico e para a busca dos recursos minerais tão necessários. O ensino das Geociências, por sua vez, não era preocupação destes cursos, ao mesmo tempo em que a educação no Brasil não se preocupou em manter os conteúdos em Geociências na formação dos professores de Ciências. O resultado foi tanto a falta de noções básicas do funcionamento do planeta por parte da população que estudou nas últimas décadas, justamente quando houve os grandes progressos nas Ciências da Terra, como também a falta de reconhecimento de sua importância na cultura geral, até mesmo por parte dos especialistas em ensino. Daí veio a idéia simplificada verificada em geral de que ecologia refere-se à vida, e não à natureza completa, ou seja, vida e ambiente físico que a gerou, modificou, foi modificado por ela e continua sustentando-a.

Por outro lado, os graves problemas sócio-ambientais originados pela atuação desastrada da sociedade nas suas atividades de ocupação e utilização do meio físico e dos materiais naturais começam a ser detectados, avaliados e divulgados, despertando naturalmente o interesse da população por temas geocientíficos. Daí o aumento desse tipo de tema em revistas, jornais, emissões de TV nacionais ou estrangeiras, além do aumento das visitas a parques e museus com temática ecológica e particularmente geológica.

O que ocorre de concreto no ensino, com a falta de ocasião para desenvolvimento integral das Geociências (origem e evolução da Terra, formação de seus materiais e de seus ambientes, condições de provável origem da vida, registro sedimentar da história geológica da vida e dos processos de interferência dos processos biológicos no planeta e dos processos geológicos na evolução da vida, condições de concentração dos recursos naturais - minerais, hídricos e energéticos e sua possibilidade de renovação, condições sustentáveis de utilização dos recursos etc.) é que os alunos são privados do conhecimento necessário para adquirir a visão de funcionamento global e interdependente da natureza, correndo o risco de desenvolverem, ao contrário do ideal, uma visão imediatista e utilitária da natureza, enquanto meio físico que proporciona soluções às necessidades modernas humanas de materiais e energia, e que também proporciona problemas de degradação, que não são compreendidos como respostas naturais às ações de interferência nos ciclos naturais.

Esta fragmentação da Geologia e das Geociências em tópicos eventualmente tratados em determinados momentos do desenvolvimento das disciplinas mencionadas não contribui para a formação de uma noção do ciclo global da natureza, da cadeia de causas e conseqüências na sucessão de eventos naturais, e da formação conseqüente de espírito crítico competente para avaliar riscos e benefício da atividade humana, cotidianamente agredindo a natureza, impedindo o curso natural da dinâmica geológica/geoquímica com os resultados de degradação ambiental conhecidos em grande parte e para julgar como deve ser a ocupação e o uso do planeta e seus materiais, o que, em verdade, está determinando o futuro da vida na Terra (Wilson, 2002; Mackenzie, 1998; Weiner, 1992; Campos, 1997; Craig et al., 1996; Chassot e Campos, 2000).

Coloca-se a questão: Como pode um cidadão ser crítico, interpretar, fazer julgamentos, atuar na sociedade (que basicamente ocupa o ambiente e usa seus materiais e fenômenos), encontrando-se privado de conhecimentos sobre o funcionamento e a organização, a gênese e a evolução do planeta e de seus ambientes e materiais, sobre as interações físicas, químicas e bioquímicas das interferências humanas na natureza?

A resposta é: não pode. O tratamento ao estudo do ambiente dado no ensino atual no Brasil (ambiente no sentido amplo: planeta Terra e sua superfície, ocupada pela sociedade) não é suficiente para formar nos educandos nem a compreensão da Terra como um sistema, nem a sensibilidade necessária para enfrentar os desafios impostos pela degradação ambiental já verificada e para contribuir para o desenvolvimento sustentável, o que pressupõe mudança de comportamento.

A seguir, são apresentadas e comentadas algumas das várias menções nos textos dos PCNEM em que fica clara a necessidade de inclusão de um programa integrador das Ciências que tratam da história e funcionamento da Terra (Geociências, e em particular a Geologia) para que seja possível o alcance dos objetivos maiores da educação básica nacional.

\section{ANÁLISE DOS PARÂMETROS CURRICULARES NACIONAIS PARA O ENSINO MÉDIO}

Com a falta de um conteúdo pleno em Ciências da Natureza, onde a Ciência da Terra ocuparia um espaço suficiente para seu desenvolvimento como disciplina autônoma que realmente é, os objetivos tão positivos dos PCNEM com 
relação à formação de cidadãos conscientes e capazes de emitir juízo de valor sobre questões do ambiente, expressos em vários momentos e de várias formas nos textos dos PCNEM, encontram-se prejudicados.

Apesar do perfeito entendimento quanto à importância do educando compreender o funcionamento do meio natural para tornar-se um cidadão capaz de avaliar e julgar as ações de interferência, ocupação e uso do ambiente e de seus materiais e agir com consciência e responsabilidade nesta questão, os PCNEM não reconhecem o papel do aprendizado integrado em Geociências no conhecimento da natureza. De fato, as Geociências são omitidas como ampla Ciência da Natureza, o que é uma pena, pois seu objeto de estudo (o planeta, seus materiais e seus fenômenos) é a sede dos fenômenos físicos, químicos e biológicos estudados no currículo escolar, podendo ser considerado que o próprio desenvolvimento da Física e da Química ocorreu com base na necessidade de compreensão dos fenômenos da natureza.

Assim, os PCN definem Ciências da Natureza apenas como Biologia, Física e Química, buscam interdisciplinaridade, que é justamente o que as Geociências permitem em seu estudo, contextualizando a dinâmica natural, considerando as definições acima, sem indicar a Geologia no sentido amplo como a Ciência de integração dos fenômenos naturais. Pregam ainda um ensino "útil à vida e ao trabalho, no qual as informações, o conhecimento, as competências, as habilidades e os valores desenvolvidos sejam instrumentos reais de percepção, satisfação, interpretação, julgamento, atuação, desenvolvimento pessoal ou de aprendizado permanente”, privando, no entanto, o educando, da compreensão global do funcionamento da natureza.

Além disso, os PCNEM indicam que aspectos relacionados a "outras” Ciências, como Geologia e Astronomia, sejam tratados em Biologia, Física e Química, no contexto interdisciplinar que preside o ensino de cada disciplina e o do seu conjunto, desconsiderando que não há professores nem de Ciências, nem de Biologia, nem de Geografia, preparados para trabalhar os conteúdos geológicos, pelos motivos já apontados.

A perspectiva orientada aos professores que atuam na educação básica, em Ciências, que é o “contexto históricopolítico-econômico-sócio-cultural”, limita o intervalo de tempo considerado a apenas alguns milhares ou algumas dezenas de milhares de anos, quando o estudo do ambiente deveria incluir 4,6 bilhões de anos, valorizando a importância da História: estudar o passado (origem e evolução da Terra e seus ambientes) para compreender o presente (características dinâmicas dos compartimentos ocupados e conseqüências das ações antrópicas) e refletir sobre as possibilidades de futuro (remediação dos problemas já criados, evitar novos problemas).
Sem a perspectiva histórica e dinâmica, a maneira como os tópicos sobre o funcionamento natural do ambiente são colocados no currículo sugere um caráter antropocêntrico e imediatista da filosofia de orientação dos conteúdos, muito embora não sejam essas as intenções expressas. Por exemplo, "explorar os aspectos sociais, políticos e econômicos da mineração de um recurso natural" quando o constituinte daquele recurso é estudado em Química, contribui para a formação de uma visão utilitária da natureza e não uma visão histórica e dinâmica, que estimularia comportamentos mais próximos da sustentabilidade.

Desta forma, a educação básica, apesar de seus objetivos definidos, não chega a dar ao cidadão a noção das conseqüências, para o futuro da vida, das interferências humanas nos processos geológicos; assim, a população não tem informações para eventualmente optar por agir de forma mais concordante, e não discordante, dos processos movidos pelas forças da natureza.

\section{Área de Ciências da Natureza, Matemática e suas Tecnologias}

\section{Item "O Sentido do Aprendizado na Área"}

Os PCNEM, no item “O sentido do aprendizado na área”, no capítulo referente às Ciências da Natureza, Matemática e suas Tecnologias, ressaltam que " $a$ interdisciplinaridade do aprendizado científico e matemático não dissolve nem cancela a indiscutível disciplinaridade do conhecimento”. No entanto, omitem as Geociências como disciplina dentro da área Ciências da Natureza, ao fragmentá-la em tópicos isolados, tratados de forma aparentemente interdisciplinar dentro de outras disciplinas, destruindo o encadeamento dos processos de evolução dos ambientes no planeta e de seus materiais. Além disso, como os professores não têm o preparo adequado (já não há professores naturalistas na ativa), as questões geológicas são na maioria das vezes, conforme a experiência escolar de todos pode confirmar, tratados de forma equivocada e desatualizada.

Afirmam que o aprendizado deve contribuir "não só para o conhecimento técnico, mas também para a formação mais ampla, desenvolvendo meios para a interpretação de fatos naturais, para a compreensão de procedimentos e equipamentos do cotidiano social e profissional, assim como para a articulação de uma visão do mundo natural e social”. Deve ainda "propiciar a construção de compreensão dinâmica da nossa vivência material, de convívio harmônico com o mundo da informação, de entendimento histórico da vida social e produtiva, de percepção evolutiva da vida,

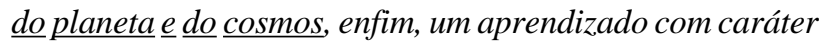
prático e crítico e uma participação no romance da cultura científica, ingrediente essencial da aventura humana". 
Não obstante, a estrutura curricular priva o educando do aprendizado da Ciência natural que pode mostrar a evolução histórica dos materiais neste ponto do cosmos onde estamos, que, a partir da nebulosa solar, formou um corpo com determinadas condições internas (sua composição e organização) e externas (localização no Sistema Solar, processos e materiais extraterrestres com influência na Terra), que mudam ao longo do tempo, segundo as leis naturais. Estas condições serviram a uma seqüência enorme de passos que foram moldando um ambiente com condições propícias à concretização de determinados processos, formando a vida, que, desde seu início, evoluiu através de processos próprios e com resultados (novas e novas espécies) cujo sucesso (proliferação e posteriores desdobramentos em novas espécies) ou fracasso (extinção) (ou seja, a seleção natural) foi sendo em parte determinado, em cada etapa, pelas condições ambientais geradas pelos processos geológicos (tectônica de placas, alterações de relevo, mudanças climáticas etc.). Assim, as condições geológicas dirigiram a evolução orgânica, a par com as condicionantes biológicas propriamente ditas, até, naturalmente, a origem e o aparente sucesso do homo sapiens (cujo berço africano foi moldado geologicamente favorecendo, provavelmente, o desenvolvimento dos hominídeos bípedes). Em outras palavras, a estrutura atual priva o aluno da fascinante aventura planetária que é o estudo da História da Terra e da História da Vida integradas, uma interferindo na outra, ao longo do tempo geológico.

Continuando, ainda no mesmo item, o texto dos PCNEM apresenta como um dos pontos de partida para o processo de aprendizagem o tratamento, como conteúdo do aprendizado matemático, científico e tecnológico, de elementos do domínio vivencial dos educandos, da escola e da sua comunidade imediata. Ora, considerando que, atualmente, todos convivemos diariamente com os problemas gerados pela degradação ambiental, nada mais lógico e eficaz do que utilizar questões como estas para conduzir o aprendizado da dinâmica natural, enfatizando sempre que possível a observação direta do meio local como fonte de informações:

a. de onde vem tudo o que utilizamos cotidianamente?

b. por que cuidar do lixo produzido?

c. por que economizar água e energia e todos os outros recursos naturais?

d. por que não construir poços de água em determinadas posições com relação às fossas sépticas?

e. por que não construir nas planícies de inundação dos rios?

f. por que não retificar os cursos d'água, ou que cuidados tomar ao fazê-lo, para evitar conseqüências indesejáveis?

g. por que não liberar no ambiente determinados produtos contendo elementos químicos tóxicos? h. por que evitar a perda de solos agrícolas?

i. por que não desmatar áreas com solos pobres?

j. por que não abusar dos fertilizantes?

l. por que utilizar proteção contra os raios UV do Sol, atualmente não filtrados adequadamente pelos problemas da camada de $\mathrm{O}_{3}$ ?

m. por que reduzir resíduos e reutilizar as coisas ao invés de usar novas, além de reciclar somente após não ter sido possível reduzir e reutilizar?

n. por que pesquisar antes de intervir no ambiente?

São questões compreendidas a partir do conhecimento do funcionamento global da natureza e estão presentes hoje nos meios de comunicação (estando ou não no domínio vivencial dos estudantes), para as quais muitas vezes os educandos e os cidadãos comuns, leigos em Ciências Naturais, não estão preparados para compreender em sua necessária profundidade, e em seu real significado e conseqüências. Assim, muitas vezes são apresentadas soluções imediatistas para determinados problemas de degradação ambiental, que apenas empurram as crises um pouco para o futuro, podendo até piorá-las.

Os PCNEM também afirmam que "um ensino médio concebido para a universalização da educação básica precisa desenvolver o saber matemático, científico $e$ tecnológico como condição de cidadania e não como prerrogativa de especialistas”. Apesar dessa afirmação, um conhecimento tão fundamental para o exercício da cidadania, como aquele referente à dinâmica e evolução terrestre não consegue ser desenvolvido de forma explícita, efetiva e ampla do ensino na educação básica.

O texto dos PCNEM menciona ainda a questão da atualização ágil dos conteúdos, no que se refere ao ensino das Ciências e tecnologias, "não para simplesmente incorporar elementos da Ciência contemporânea por conta de sua importância utilitária, mas para prover os alunos de condições para desenvolver uma visão de mundo atualizada". Novamente, fica claro o problema criado pela falta de Geociências no ensino, dando a oportunidade para a formação de uma idéia “utilitária” por parte dos alunos quando tópicos isolados são apresentados. Muito significativo neste ponto é o exemplo da Química; quando do estudo de elementos químicos que constituem recursos minerais, são explorados os aspectos sociais, políticos e econômicos da mineração daquele recurso, o que contribui para a formação de uma visão utilitária da natureza (os recursos estariam aí para servir à sociedade industrial) e não uma visão histórica e dinâmica da natureza (os recursos são limitados, são circunstanciais na dinâmica natural do planeta, tendo sido concentrados ao longo de milhões ou bilhões de anos, por uma sucessão de processos naturais que jamais poderão ser repetidos artificialmente, e sua retirada, modificação e 
decorrente produção de resíduos causa desequilíbrios no curso da evolução natural, muito além do que a humanidade pode controlar).

No mesmo contexto insere-se o gerenciamento dos recursos hídricos: os rios são tratados como extensões das tomadas das instalações elétricas ou como parte das tubulações da rede de água e esgoto, quando deveriam ser compreendidos como órgãos de um grande sistema, que levam condições para a manutenção e desenvolvimento da vida através da superfície terrestre. Quando compreendidos como etapa do ciclo da água e fruto de uma história de bilhões de anos, os rios serão tratados com mais cuidado. O que se verifica até o momento é um descuido colossal, a ponto de destacar o Brasil, particularmente a região sudeste, no cenário mundial em termos de poluição fluvial.

Os PCNEM também mencionam alguns temas como energia e modelos de átomos e moléculas como temas que transcendem à Física e à Química, chegando à Biologia molecular, ignorando completamente os materiais mais primitivos (e mais úteis) que estão à nossa volta, os materiais geológicos, justamente constituídos por átomos e por moléculas, e formados, obviamente, por processos que envolveram energia, e ainda envolvem, na evolução dinâmica que qualquer material tem. Que laboratório incrível não é a Terra, à disposição para se estudar todos estes temas, reunidos nas Ciências da Terra, que o ensino insiste em ignorar.

A questão da poluição e da contaminação, urbana ou rural, de caráter físico, químico ou biológico, como não poderia deixar de ser, também é mencionada, ressaltando que ela "não é do âmbito de nenhuma disciplina isolada dentro das Ciências da Natureza, necessitando mesmo da inclusão das perspectivas das Ciências Humanas”. Pois podemos perceber que esta questão, que interfere diretamente no objeto de estudo da Biologia, é sim do âmbito de uma disciplina: a Geologia, ou, de uma forma mais ampla, as Geociências ou a Ciência do Sistema Terra, que abrange, integra e articula os aspectos físicos e químicos do meio natural e que continua distante do ensino brasileiro.

Tratando da interdisciplinaridade, o texto menciona o princípio físico da "conservação de energia, essencial na interpretação dos fenômenos naturais e tecnologias, que pode ser verificado em processos de natureza biológica, como a fermentação, ou em processos químicos (esquecendo-se que processos químicos naturais, quando não são de natureza biológica são de natureza geológica) como $a$ combustão" etc., mencionando ainda evaporação, condensação, dissolução, citando sua participação no ciclo da água e na fotossíntese, afirmando ainda que "esses processos são essenciais para a compreensão da apropriação humana dos ciclos materiais e energéticos, como o uso de hidreletricidade e da biomassa”. Neste ponto, novamente fica muito evidente a falta de equilíbrio causada pela ausência de Geociências no currículo. Não fosse por determinadas etapas na evolução planetária, a atmosfera não teria se tornado transparente aos raios solares e não teria tido início a realização da fotossíntese. Não fosse a fotossíntese, não teríamos ambiente progressivamente oxidante no passado geológico e não haveria, por exemplo, as imensas jazidas de ferro, no Brasil e em outras partes do mundo, e nem a vida teria seguido o caminho evolutivo que seguiu. Todas as reações/processos mencionados estão ocorrendo nos materiais geológicos há 4,6 bilhões de anos, todos os dias, deixando seus registros (os solos, as rochas, as águas), que podem ser manipulados e interpretados como testemunhos da história do planeta, além de serem responsáveis pela formação de muitos dos bens minerais que fornecem elementos e substâncias para a indústria de transformação. Como exemplos, incluindo as reações químicas mencionadas nos PCNEM, os evaporitos vêem da evaporação de corpos de água carregados em determinados elementos, a condensação é etapa do ciclo da água, a dissolução ocorre no intemperismo químico, processo fundamental na formação dos solos etc.

Ainda tratando da interdisciplinaridade, o texto explica que:

"a consciência desse caráter interdisciplinar ou transdisciplinar, numa visão sistêmica, sem cancelar o caráter necessariamente disciplinar do conhecimento científico mas completando-o, estimula a percepção da inter-relação entre os fenômenos, essencial para boa parte das tecnologias, para a compreensão da problemática ambiental e para o desenvolvimento de uma visão articulada do ser humano em seu meio natural, como construtor e transformador deste meio".

Ora, como estimular a compreensão da problemática ambiental sem a Ciência que apresenta a Terra como um sistema, ou seja, as Geociências? Como promover o desenvolvimento de uma visão articulada do ser humano como construtor/transformador de seu meio sem a noção de funcionamento global desse meio?

Em ritmo crescente, os profissionais da comunicação estão produzindo centenas de vídeos e outros materiais usando a Ciência do Sistema Terra para explorar o ambiente e os problemas ambientais e sócio-ambientais, e o estudante brasileiro (diferentemente de outros) encontra-se sem condições de compreender amplamente esses materiais, e sem base para aplicar as informações em sua vida. Ainda se diz, no ensino fundamental e médio brasileiro, que o manto terrestre é líquido (por falta de aplicação da Física: alívio de pressão funde o material sólido do manto, por isso os vulcões expelem lava líquida), que lençol de água subterrânea são rios dentro da terra, que água poluída é filtrada pelo solo, que Pangea foi o primeiro supercontinente etc., evi- 
denciando os efeitos perversos cumulativos da falta do estudo do sistema Terra no ensino fundamental e médio: até os professores que poderiam ministrar esses conteúdos são especialistas, não tendo desenvolvido uma visão global do ambiente que ocupamos.

\section{Item "Competências e Habilidades" na área de Ciências Naturais, Matemática e suas Tecnologias}

Finalmente, na apresentação do elenco dos principais objetivos formativos, praticamente todos os itens contemplam o aprendizado de Geociências, reconhecendo em teoria (mas não dando condições na prática) a melhora que representaria a inserção mais ampla e efetiva desta Ciência na educação básica. Alguns objetivos são aqui destacados por sua imediata relação com a Ciência em questão:

1. no item "Representação e Comunicação":

"Ler e interpretar textos de interesse científico e tecnológico”.

"Interpretar e utilizar diferentes formas de representação (tabelas, gráficos, expressões, ícones...)”;

2. no item "Investigação e Compreensão":

"Desenvolver a capacidade de questionar processos naturais e tecnológicos, identificando regularidades, apresentando interpretações e prevendo evoluções”.

"Fazer uso dos conhecimentos da Física, da Química e da Biologia para explicar o mundo natural e para planejar, executar e avaliar intervenções práticas”.

"Aplicar as tecnologias associadas às Ciências Naturais na escola, no trabalho e em outros contextos relevantes para sua vida";

3. no item "Contextualização Sócio-Cultural”:

"Compreender e utilizar a Ciência como elemento de interpretação e intervenção, e a tecnologia como conhecimento sistemático de sentido prático".

"Utilizar elementos e conhecimentos científicos $e$ tecnológicos para diagnosticar e equacionar questões sociais e ambientais".

"Associar conhecimentos e métodos científicos com a tecnologia do sistema produtivo e dos serviços".

"Reconhecer o sentido histórico da Ciência e da tecnologia, percebendo seu papel na vida humana em diferentes épocas e na capacidade humana de transformar o meio".

"Compreender as Ciências como construções humanas, entendendo como elas se desenvolveram por acumulação, continuidade ou ruptura de paradigmas, relacionando o desenvolvimento científico com a transformação da sociedade”.

"Entender a relação entre o desenvolvimento de Ciências Naturais e o desenvolvimento tecnológico e associar as diferentes tecnologias aos problemas que se propuser $e$ se propõe solucionar".

"Entender o impacto das tecnologias associadas às Ciências Naturais, na sua vida pessoal, nos processos de produção, no desenvolvimento do conhecimento e na vida social”.

\section{Item "Conhecimentos em Biologia"}

O texto menciona ainda que:

"o aprendizado disciplinar em Biologia, cujo cenário, a biosfera, é um todo articulado, é inseparável das demais Ciências” e que:

“A própria compreensão do surgimento e da evolução da vida nas suas diversas formas de manifestação demanda uma compreensão das condições geológicas e ambientais reinantes no planeta primitivo. $O$ entendimento dos ecossistemas atuais implica um conhecimento da intervenção humana, de caráter social e econômico, assim como dos ciclos de materiais e fluxos de energia”.

Novamente, não é possível compreender as condições geológicas reinantes no planeta primitivo sem a compreensão de sua evolução integral. Além disso, deve ser complementado que o exposto demanda a compreensão da evolução do planeta e sua interação com a evolução da vida (planeta e vida transformando-se mutuamente ao longo do tempo geológico). Ou seja, o estudo da História Natural (Biologia e Geologia integradas) satisfaria melhor os objetivos expostos nos PCNEM do que a fragmentação existente hoje em dia. Finalmente, no contexto do que os PCNEM parecem desejar para a educação no país, não parece razoável que o planeta, a geosfera, cenário das Geociências, não seja considerado um todo articulado, que justifique um estudo da mesma forma articulado, da mesma forma que se considera a biosfera, cenário da Biologia.

O documento justifica o estudo de certos detalhes biológicos, afirmando que não são "luxo acadêmico"; dá o exemplo da noção de como operam os mecanismos de codificação genética, baseado na necessidade em se entender e emitir julgamento sobre testes de paternidade pela análise de DNA, a clonagem de animais ou a forma como certos vírus produzem imunodeficiências, todos temas da atualidade. Qual seria a justificativa, então, para privar o aluno da educação básica de Geociências, já que, sem os conteúdos referentes a esta área, não se pode emitir julgamento sobre os riscos de ocupação de certas áreas da paisagem, sobre o caráter renovável ou não dos recursos materiais que utilizamos, sobre a relação risco benefício nas opções de usinas hidrelétrica, termoelétrica ou nuclear para a geração de energia elétrica, 
sobre a conveniência de separar-se ou não o lixo reciclável, sobre os locais mais adequados para a deposição de lixo, sobre a necessidade de tratar os esgotos, sobre a viabilidade de soluções propostas para determinados problemas, entre tantos outros aspectos de nossa vida cotidiana. Não são absolutamente menos importantes que os "detalhes biológicos” mencionados pelos PCNEM.

Em seguida, o texto faz menção ao entendimento dos ecossistemas atuais, que "implica em conhecimento da intervenção humana e dos ciclos de materiais e fluxos de energia”. Como entender a fragilidade dos ecossistemas atuais perante a intervenção humana sem ter ao menos uma compreensão básica do encadeamento de processos formadores, ou seja, da história dos ecossistemas?

Na parte referente à apresentação dos "Conhecimentos de Biologia”, o documento menciona como objetivos do ensino "reconhecer determinados elementos e condições da Terra primitiva para a compreensão da origem da vida". Porque dar apenas à Biologia a responsabilidade por explicar tal tema, se são as condições geológicas que aí atuaram?

Adiante, o texto cita Biologia, Física, Química, Geografia, História e Filosofia como "campos do conhecimento que contribuem para o estudo da dinâmica ambiental, possibilitando ao aluno relacionar conceitos aprendidos nessas disciplinas, numa conceituação mais ampla de ecossistema”. Continua, afirmando que:

"um aspecto da maior relevância na abordagem dos ecossistemas diz respeito à sua construção no espaço e no tempo e à possibilidade da natureza absorver impactos e se recompor", e que

"o estudo da sucessão ecológica permite compreender a dimensão espaço-temporal do estabelecimento de ecossistemas, relacionar diversidade e estabilidade de ecossistemas, relacionar essa estabilidade a equilíbrio dinâmico, fornecendo elementos para avaliar as possibilidades de absorção de impactos pela natureza”.

Parece estranho, e só pode ser resultado do equívoco histórico, que o ensino de Ciências da Natureza ignore Geologia, Geofísica, Geoquímica, dentro das Geociências, como campos do conhecimento que abrangem, integram, articulam e interpretam os aspectos físicos e químicos, em estreita relação com a Biologia, e que podem promover a compreensão da formação e da evolução dos ecossistemas.

Mais um exemplo em que a necessidade do estudo integral de Geociências é evidenciada ocorre quando os PCNEM tratam das:

"relações entre alterações ambientais e modificações dos seres vivos, estas últimas decorrentes do acúmulo de alterações genéticas, precisam ser compreendidas como eventos sincrônicos, que não guardam simples relação de causa e efeito; a variabilidade, como conseqüência de mutações e de combinações diversas de material genético, precisa ser entendida como substrato sobre o qual age a seleção natural; a própria ação da natureza selecionando combinações genéticas que se expressam em características adaptativas, também precisa considerar a reprodução, que possibilita a permanência de determinado material genético na população. A interpretação do processo de formação de novas espécies demanda a aplicação desses conceitos, o que pode ser feito, por exemplo, pelos alunos, se solicitados a construir explicações sobre o que poderia determinar a formação de novas espécies, numa população, em certas condições de isolamento geográfico e reprodutivo".

Inúmeros exemplos de fenômenos geológicos moldando essas modificações dos seres vivos estão disponíveis nos meios de comunicação, em livros, revistas, filmes, animações... menos na escola brasileira! É o estudo da dinâmica geológica global, que pode dar aos educandos a idéia evolutiva do meio, necessária ao alcance dos objetivos dos PCNEM. Cabe ainda ressaltar que os testemunhos geológicos da evolução da vida, quais sejam, os fósseis, são preservados nas rochas sedimentares, que guardam ainda informações sobre o ambiente de deposição e, conseqüentemente, o ambiente de vida dos organismos fossilizados e as modificações sofridas pelo ambiente.

Os PCNEM chegam a mencionar a história geológica da vida e a escala do tempo geológico no enfoque evolutivoecológico do estudo da diversidade dos seres vivos. Repetidamente, assim, o documento mostra, em suas entrelinhas, a importância do estudo das Geociências e seus aspectos geológicos.

\section{Item "Conhecimentos em Química"}

Novamente tratando da Química, agora em item específico, o documento fala de temas geocientíficos quando menciona que “a Química está presente e deve ser reconhecida nos elementos e medicamentos, nas fibras têxteis e corantes, nos materiais de construção e nos papéis...” etc. Na verdade, estes constituintes do cotidiano são produtos de transformação industrial ou artesanal de recursos naturais, formados por processos naturais, geológicos ou biológicos. Não se justifica, portanto, a diferença de tratamento entre Biologia (apresentada de forma integral, até com “detalhes” que poderiam parecer “luxo acadêmico”) e Geologia (apresentada de forma fragmentada, desatualizada, fora de seu contexto de ciência autônoma, com papel articulador e central numa visão interdisciplinar do tratamento do planeta 
Terra como um todo). A própria Química tem sua história baseada na Geoquímica, pois foi nos constituintes geológicos, como não poderia deixar de ser, que os elementos químicos foram sendo descobertos e estudados, e esta informação enriqueceria ainda mais a apresentação dos conteúdos relacionados.

A sobrevivência do ser humano, individual e grupal, nos dias de hoje, é mencionada como algo que demanda cada vez mais os conhecimentos químicos que permitam a utilização competente e responsável dos materiais, reconhecendo as implicações sócio-políticas, econômicas e ambientais de seu uso. Dá como exemplo "o desconhecimento de processos ou o uso inadequado de produtos químicos", que "podem estar causando alterações na atmosfera, hidrosfera, biosfera e litosfera, sem que, muitas vezes, haja consciência dos impactos por eles provocados”. Justamente, como reconhecer essas alterações sem conhecer o planeta como um sistema em que atmosfera, hidrosfera, biosfera e litosfera, além das outras esferas geoquímicas não mencionadas (certamente por terem menor visibilidade, mas nem por isso menor importância), interagem continuamente, e sem perceber a pequenez do tempo humano no tempo geológico e a grandiosidade de suas interferências em tempo tão pequeno. Pode-se imaginar, estimulados por estas observações, que enriquecedor será para a sociedade quando o cidadão brasileiro tiver desenvolvido, na escola, a sensibilidade e o conhecimento que permitirão dar o justo peso e a justa medida às suas ações cotidianas, tendo a consciência para optar entre economizar ou não água, energia elétrica, derivados de petróleo, impermeabilizar ou não o solo de suas propriedades, ocupar ou não uma área de manancial, uma encosta, desmatar ou não um pedaço de terra, e assim por diante.

"As transformações químicas do meio (como alterações na atmosfera, hidrosfera, biosfera e litosfera) por desconhecimento de processos ou uso inadequado de produtos químicos", segundo os PCNEM, ocorrem por falta de "visão integrada da Química, da Física e da Biologia, recorrendo ao instrumental matemático apropriado, o que mostra a necessidade das interações entre esses saberes”. Mais uma vez verifica-se uma enorme contradição entre as intenções dos PCNEM e a prática preconizada para o seu alcance. Isto porque a Ciência do Sistema Terra ocupa-se da natureza mesmo antes do surgimento da vida; ocupa-se de todos os fenômenos físicos, químicos e físicoquímicos que ocorrem no planeta, sucedendo-se na História da Terra e delineando a formação e evolução dos materiais e dos ambientes, que são matéria-prima e sede de todas as atividades sócio-econômicas. Naturalmente, é a Ciência que tem condições de avaliar as transformações químicas mencionadas, enquanto a Química e a Física tratam dos materiais isolados do meio.
No item sobre os “Conhecimentos em Química”, o texto dos PCNEM insiste em várias partes em fenômenos geoquímicos, como que procurando dar um sentido prático natural (já que Química está em Ciências da Natureza) aos conceitos químicos, de constituição dos materiais e de processos químicos. É bom lembrar que a própria história da Química envolveu desde sempre a Geoquímica, já que foi sempre nos materiais geológicos que os elementos químicos foram sendo descobertos e caracterizados, e suas propriedades compreendidas, como já foi necessário ressaltar anteriormente.

Como para Física, convém sempre dar referência natural, ou seja, geológica, aos conceitos e fenômenos tratados nestas Ciências, para que possam os educandos compreender porque Física e Química são consideradas Ciências Naturais (Ciências que fornecem os conceitos para a explicação do funcionamento da natureza). Como para a exposição das pretensões do ensino para os conhecimentos de Biologia e de Física, no entanto, também no item sobre conhecimentos em Química, o documento dos PCNEM comete o equívoco de fragmentar o conhecimento geocientífico, dando continuidade à situação de perda de oportunidade para apresentar a dinâmica terrestre global como integradora dos processos físicos e químicos (e também biológicos).

Assim, menciona a necessidade, para se compreender a interação do ser humano com a atmosfera, de "entender como a atmosfera formou-se e permitiu a manutenção da vida na Terra e como se tornou fonte de materiais úteis à sobrevivência humana". Esta questão da evolução da atmosfera é tema da Geoquímica, profundamente ligada à evolução das partes interiores do planeta, já que a atmosfera formou-se por degaseificação da Terra, em processos geológicos, passando por profundas mudanças em sua composição química, em parte essencial devido à interação com os processos biológicos. Cabe ainda um reparo a fazer quanto à menção de sobrevivência humana sem incluir o restante da biosfera, novamente dando um viés antropocêntrico para a questão.

Menciona logo depois que:

“os estudos a partir da atmosfera, hidrosfera, litosfera e biosfera são muito apropriados para aprofundar a interdisciplinaridade, pois o entendimento da participação de cada uma dessas partes no conjunto e a do próprio conjunto requerem não só o conhecimento específico, mas fundamentalmente o entendimento dos resultados das interações entre os conhecimentos químicos e os conhecimentos físicos, biológicos e geológicos”.

Como em tantos outros momentos, o documento deixa nas entrelinhas, mas não conclui que a Geologia em particular, ou as Geociências como um todo, integram todas as 
esferas geoquímicas mencionadas da superfície do planeta e que a Terra como um todo é o objeto de estudo ideal para a interação dos conhecimentos das várias Ciências naturais e para a interpretação dos fenômenos na natureza.

Há ainda citações de processos da tecnologia, como a metalurgia, que seriam utilizados não apenas como temas para aprendizado de conceitos em Química, mas para exame no contexto de um estudo mais amplo da litosfera. Embora pareça estranho estudar a litosfera em Química, existindo toda uma Ciência que a estuda em seus aspectos químicos (a Geoquímica) e ainda sob outros aspectos, a justificativa é que, com este exame, pode-se "estudar fontes naturais de minérios dos quais se extraem os diferentes metais, os processos químicos envolvidos nessas transformações, as implicações sociais, econômicas e ambientais decorrentes da obtenção e do uso desses metais”. Sem dúvida, estes temas são de grande importância; porém, sua apresentação desconectada da história geológica de geração dos recursos minerais, acidentes na evolução do planeta, pode dar um caráter eminentemente "utilitário” aos recursos, que são finitos, e cuja extração e utilização deve ser feita à luz do conhecimento das conseqüências desses atos. A sensibilidade para essas questões não será desenvolvida com essa fragmentação da Ciência da Terra, integradora por natureza.

\section{Item "Conhecimentos em Física"}

No item “Conhecimentos em Física”, o texto dos PCNEM menciona isoladamente fenômenos geológicos ou tecnologias associadas que deveriam ser tratados em sala de aula, como técnicas de extração de água subterrânea. Indica ainda "que seria interessante que o estudo da Física no Ensino Médio fosse finalizado com uma discussão de temas que permitissem sínteses abrangentes dos conteúdos trabalhados”.

Considerando que o planeta Terra é justamente a sede dos fenômenos de todos os processos físicos naturais e onde as forças físicas da natureza se manifestam na formação e transformação contínua dos materiais e dos ambientes, as sínteses citadas seriam abrangentes e enriquecedoras, pois aliariam o conhecimento físico através dos materiais naturais com a compreensão da interdependência dos processos. A Tectônica de Placas, por exemplo, com seus possíveis mecanismos de movimentação e suas conseqüências de deformação das rochas, abrange um grande número de conceitos físicos que podem aí ser integrados. A dinâmica externa, conjunto de processos que remodela a superfície continuamente, também. O mesmo para o estudo indireto do interior do planeta, com a utilização da medida da variação de parâmetros físicos para interpretação da diferenciação interna e até da composição, do estado físico e da densidade de cada setor, a exemplo do estudo indireto dos organismos através de princípios físicos. Indo para questões mais palpáveis, poderiam ser explorados os métodos geofísicos para o conhecimento do substrato raso, que são valiosos para a identificação de aqüíferos entre outras aplicações que otimizam a utilização dos recursos naturais.

A própria história da evolução do conhecimento do planeta está associada à história da Física, que possibilitou, com o tempo, a aquisição de informações físicas mais e mais refinadas sobre os materiais geológicos. Fica claro, assim, o importante apoio que enriqueceria o ensino de Física, se Geologia constasse como Ciência integradora dos processos naturais do planeta, dando um sentido global a todos os fenômenos físicos e suas leis.

\section{Item "Rumos e Desafios"}

O item final da Parte III, sobre Ciências da Natureza, Matemática e suas Tecnologias, apresenta os Rumos e Desafios para a educação nesta área. Entre outras considerações, o texto descreve a evolução das propostas pedagógicas no Brasil desde a LDB 4024/61, colocando que, já na década de 70, “o modelo de industrialização acelerada impôs, em todo o mundo, custos sociais e ambientais altos, de forma que, particularmente no ensino fundamental, os problemas relativos ao meio ambiente e à saúde humana começaram a estar presentes em currículos de Ciências”.

O comentário a ser feito nesta parte é que, nos países onde a cultura natural (História Natural) permaneceu forte, como é o exemplo dos países da Europa ocidental, o estudo global do meio físico continuou integrado ao estudo da vida, contribuindo para a aquisição de idéias mais precisas e completas sobre o funcionamento natural das coisas e as conseqüências das interferências humanas; houve até épocas em que a História de uma nação incluía a História Natural (Geologia e Biologia) da região ocupada por aquela nação, com a justificativa de que o meio natural moldava a cultura da sociedade ali instalada. Nestes países, é comum encontrar literatura em Geociências dirigida a leigos ou a professores e estudantes do ensino secundário em nível de profundidade semelhante ao dos primeiros anos de universidade no Brasil (Allègre, 1983; Caron et al., 1992; Chapel et al., 1996; Lemoine et al., 2000; Siemer et al., 2003).

No exemplo do Brasil, como o meio físico era há muito tempo já tratado apenas pela perspectiva da Geografia (escala de tempo limitada) ou da Biologia (que havia se afastado da vertente geológica da História Natural, não tendo acompanhado a evolução dos conhecimentos em Ciências da Terra), isso não foi possível, e o resultado tem sido uma população cada vez mais distante das soluções dos problemas sócioambientais, sem compreender a dinâmica natural global, e tentando resolver com mais interferências os problemas causados pelas interferências anteriores, numa cadeia sem fim (vide problemas das inundações nas grandes cidades ou da 
perda de solos agrícolas e da poluição dos solos e águas). O desconhecimento das Geociências faz com que, mesmo buscando soluções, a população e até mesmo órgãos do governo atribuam a profissionais de outras áreas a tarefa de resolução de problemas essencialmente geológicos, ligados principalmente ao subsolo e às águas subterrâneas.

\section{Área de Ciências Humanas e suas Tecnologias: Geografia e História}

Aqui, o diálogo interdisciplinar pode aproximar as Ciências Humanas das Naturais, em reflexões conjugadas ou em ópticas distintas sobre os mesmos problemas.

Na parte introdutória do item relativo à área de Ciências Humanas e suas Tecnologias, os PCNEM apresentam que, em sua constituição, historicamente, as Ciências Humanas "voltaram-se para o homem, não com a preocupação de formá-lo, mas de compreendê-lo. Assim fazendo, passaram a circundar em torno de um mesmo objeto principal: o humano, explorado em todas as suas vertentes”. E assim, a Geografia, enquanto disciplina que estuda as relações entre a natureza e o ser humano, tem ficado restrita às últimas dezenas de milhares de anos, tempo de existência do homo sapiens, o que, naturalmente, não dá conta do tempo natural terrestre, ou seja, do tempo geológico, de 4,6 bilhões de anos, e que é necessário de ser considerado para atingir a compreensão do passado, presente e futuro das relações da biosfera com o meio físico e das conseqüências das relações da sociedade industrial com a natureza.

Segundo o texto dos PCNEM, "As Ciências Naturais, ao longo de sua constituição histórica, vêm atuando como indutoras de transformações sociais e econômicas, idealizando e construindo mecanismos de controle da natureza", e ainda "Esse esforço de controle teve grande importância para o nascimento, desde a segunda metade do século XVIII, das sociedades capitalistas amparadas na indústria e na técnica”. Continuando o próprio texto dos PCNEM, as Ciências Humanas, "Seguindo a inspiração positivista, transpunham para o campo da cultura os mesmos pressupostos aplicáveis ao estudo da natureza” ... “e a Geografia serviu para mapear as potencialidades dos territórios nacionais ou daqueles a serem conquistados (tarefa realizada talvez mais pelos naturalistas), além de exaltar as riquezas de cada 'solo pátrio'”. Justificando as novas concepções da Educação, o texto afirma que "No século $X X$, sem que desaparecessem as concepções anteriores, novas perspectivas teóricas têm procurado minar as certezas positivas, incorporando orientação mais relativista às análises”.

Os PCNEM ressaltam ainda "a globalização, uma nova ordem mundial com novos conflitos e tensões, a crise dos Estados-nação, a formação de blocos econômicos, a desterritorialização de muitos grupos humanos” e que, neste quadro, "as questões ambientais conferem novos significados à sociedade como um todo e em suas partes".

Assim, o documento dos PCNEM apresenta o momento atual como "de se estruturar um currículo em que o estudo das Ciências e o das humanidades sejam complementares e não excludentes. Busca-se, com isso, uma síntese entre humanismo, Ciência e tecnologia, que implique a superação do paradigma positivista, referindo-se à Ciência, à cultura e à história”.

Destaca-se novamente aqui a importância que podem ter as Geociências na construção do conhecimento mais real e amplo do funcionamento do mundo.

\section{Item "Conhecimentos em Geografia"}

Como nunca foi negado, a Geografia preconizada pelos PCNEM assume suas responsabilidades na questão ambiental, mas não se coloca em associação suficiente com as demais Geociências.

A Geografia, "ao buscar compreender as relações econômicas, políticas, sociais e suas práticas nas escalas local, regional, nacional e global, concentra-se e contribui, na realidade, para pensar o espaço enquanto uma totalidade na qual se passam todas as relações cotidianas e se estabelecem as redes sociais nas referidas escalas". Assim, em que pese a Geografia ter sido redefinida como ciência social, o viés do espaço físico estudado pela Geografia Física nunca deixou de ter importância fundamental nos seus estudos, e é justamente o elo de ligação com a Geologia, que se ocupa da parte genética e evolutiva do espaço ocupado pela sociedade. Esta dinâmica, inserida no exercício de mudança freqüente de escala, tanto temporal como espacial, feita por quem se aprofunda em Geociências, permite compreensão mais ampla das relações do ser humano com o ambiente, e representa a contribuição que o estudo mais completo da natureza pode dar aos objetivos da LDBEN.

Alguns destaques do significado e do objetivo do estudo de Geografia no ensino médio podem ser feitos, todos apontando para a necessidade de valorização do estudo concreto do meio ambiente realizado pela Ciência do Sistema Terra, e que deveria estar intimamente associado à tradicional Geografia Física:

1. “Compreender o desenvolvimento da sociedade como processo de ocupação de espaços físicos e as relações da vida humana com a paisagem, em seus desdobramentos político-sociais, culturais, econômicos e humanos".

2. “A dimensão temporal, inscrita na memória que constrói a identidade coletiva e na dinâmica dos processos sociais, completa-se na dimensão espacial, que territorializa os eventos e processos. Essa dimensão espacial 
situa a ação humana em suas complexas relações com a paisagem natural, que é culturalizada a cada momento de interação".

3. "Os conhecimentos de Geografia e de Economia estão aqui apontados nas relações de produção $e$ apropriação de bens, que conformam as dimensões materiais da existência concreta do homem e geram desdobramentos diversos sobre a vida em sociedade. Os processos de ação e controle dessas paisagens implicam responsabilidades sociais, coletivas, que assegurem a existência comum e a sobrevivência futura das comunidades humanas".

4. "Nunca o espaço do homem foi tão importante para o desenvolvimento da história. Por isso, a Geografia é a Ciência do presente, ou seja, é inspirada na realidade contemporânea. O objetivo principal destes conhecimentos é contribuir para o entendimento do mundo atual, da apropriação dos lugares realizada pelos homens, pois é através da organização do espaço que eles dão sentido aos arranjos econômicos e aos valores sociais e culturais construídos historicamente".

No item referente às competências e habilidades a serem desenvolvidas em Geografia, no ensino médio, podem ser feitos também alguns destaques, visando à demonstração da necessidade de aproximação dos conteúdos e objetivos aos conteúdos geocientíficos:

1. "Orientar o seu olhar para os fenômenos ligados ao espaço, reconhecendo-os não apenas a partir da dicotomia sociedade-natureza, mas tomando-os como produto das relações que orientam seu cotidiano, definem seu 'locus espacial' e o interligam a outros conjuntos espaciais".

2. "Reconhecer as contradições e os conflitos econômicos, sociais e culturais, o que permite comparar $e$ avaliar qualidade de vida, hábitos, formas de utilização e/ou exploração de recursos e pessoas, em busca do respeito às diferenças e de uma organização social mais equânime".

3. "Tornar-se sujeito do processo ensino-aprendizagem para se descobrir convivendo em escala local, regional, nacional e global. A autonomia que a identidade do cidadão confere é necessária para expressar sua responsabilidade com o seu lugar-mundo, através de sua identidade territorial".

4. "Analisar e comparar, interdisciplinarmente, as relações entre preservação e degradação da vida no planeta, tendo em vista o conhecimento da sua dinâmica e a mundialização dos fenômenos culturais, econômicos, tecnológicos e políticos que incidem sobre a natureza, nas diferentes escalas - local, regional, nacional e global”.

\section{Item "Conhecimentos em História"}

Em História também há uma noção desenvolvida que diz respeito ao tempo geológico:

"Quando situamos o homem numa escala planetária, da formação das paisagens, das plantas e outros animais, pensando no 'tempo da natureza', os referenciais se transformam. Percebemos o 'lugar' que o homem ocupa na história do planeta em uma outra dimensão temporal. O tempo geológico determina outras formas de referenciar o tempo social. Ao situarmos a idade da Terra em aproximadamente 4,5 bilhões de anos, podemos entender que a história das sociedades humanas corresponde a uma pequena fração de tempo da história do planeta. A compreensão da escala de tempo pode situar o papel do homem no processo de transformação da natureza, assim como dimensionar, para além do tempo presente, os limites e o poder das ações humanas. Dentre os aspectos importantes decorrentes da abordagem dessas temporalidades, destaca-se a reciprocidade das transformações promovidas pela natureza sobre a vida dos homens $e$ como estes mudam os ritmos de tempo da natureza".

Justamente o estudo da escala de tempo geológico, da seqüência de eventos naturais como cadeia interdependente de processos, é um dos trabalhos em educação que pode promover o surgimento da sensibilidade do educando para a dimensão do que pode a humanidade em sua luta constante para controlar o planeta e modificá-lo, levando à reflexão sobre o que seria melhor: modificar o meio com grandes obras discordantes das forças naturais, sujeitas, portanto, ao desequilíbrio e a conseqüências indesejáveis, ou buscar o caminho para ocupar o meio adaptando-se, concordando com os processos naturais, dele se valendo para construções mais estáveis e duradouras?

Segundo Seibold (1993), a história das relações da humanidade com a natureza pode ser vista como tendo se iniciado por uma fase primitiva, de adaptação e submissão à natureza, inclusive com o desenvolvimento de aspectos religiosos de adoração às forças naturais, passando por uma fase ofensiva, quando a humanidade, bastante antropocêntrica, buscou sujeitar a Terra aos desejos do ser humano de bens, conforto, energia e longevidade. Nesta fase, a exploração dos recursos ocorreu em velocidade maior do que o desenvolvimento da compreensão do significado deste comportamento. Atualmente, a humanidade precisa defender-se dos problemas criados nesta evolução, já que a explosão populacional e o aumento de consumo de recursos naturais causam uma pressão no ambiente que não é mais absorvida sem respostas perigosas à estabilidade das condições favoráveis à vida na 
superfície da Terra. Por isto, este autor classifica a fase atual como uma nova fase ofensiva, mas desta vez no sentido de investigar as leis que governam o comportamento dos materiais e processos naturais, e usar este conhecimento para prever e remediar riscos e problemas, ao que podemos acrescentar, mudar o comportamento da sociedade, uma vez difundidos estes conhecimentos através da educação escolar.

\section{CONCLUSÃO}

Do exame do texto de apresentação dos Parâmetros Curriculares Nacionais para o Ensino Médio e da análise principalmente de seu conteúdo em Ciências da Natureza, Matemática e suas Tecnologias, conclui-se que, para atingir os objetivos pretendidos de formar cidadãos conscientes, capazes de avaliar e julgar as atividades humanas que envolvem a ocupação e o uso do ambiente e dos materiais naturais, é necessária, de alguma forma, a introdução efetiva e abrangente das Geociências, não como fragmentos, como ocorre atualmente, mas como um todo íntegro.

O que se propõe nesta conclusão é que seja dada aos educandos a oportunidade de estudar a natureza em toda a sua integridade complexa, como algo que evoluiu muitíssimo antes da humanidade aparecer com toda sua força criadora e transformadora, de compreender a importância colossal do tempo e do espaço fora do padrão da vida humana, o que pode levar a uma postura de maior respeito e cuidado com o ambiente. Esta proposta aparece como reação ao que atualmente se apresenta como estudo da natureza, limitado à vida, em Biologia e em Ciências, ou limitado à última fração do tempo geológico, sem a base química e física, em Geografia (Física). Quando inevitavelmente temas geológicos são tratados, fundamentais que realmente são, o que é reconhecido pelos PCNEM, inúmeros equívocos aparecem e multiplicam-se, pois a grande maioria dos professores não teve oportunidade para um preparo específico.

Outra forma de apresentação do conhecimento em Ciências da Terra, ao contrário, promoveria a compreensão do caráter de sistema dinâmico que a Terra possui e de sua história de bilhões de anos de processos naturais físicos e químicos - registrados e mensuráveis, que foram modificando e sendo modificados pela vida, desde sua origem -, permitindo o desenvolvimento de uma percepção maior da realidade natural e do significado e papel que a humanidade pode ter na história da Terra a partir de quando suas interferências nos processos naturais começaram a desviar o rumo da evolução terrestre, notadamente em sua superfície.

Enquanto o funcionamento da natureza for apresentado de forma fragmentada, a mesma disposição de interferência prevalecerá e as Ciências da Terra não poderão contribuir para o desenvolvimento de um comportamento de proteção do ambiente e dos recursos naturais, mantendo-se a noção atual de que a sociedade pode satisfazer suas necessidades materiais como se suas ações de ocupação do meio e de utilização dos recursos não tivessem grandes conseqüências, ou que estas pudessem ser fácil e/ou rapidamente resolvidas com mais interferências.

Sem querer isolar a Ciência do Sistema Terra das outras disciplinas, muito pelo contrário, mesmo sendo uma Ciência autônoma, seus temas poderiam estar ao menos mais agrupados, de forma a possibilitar a formação de uma idéia global e seqüenciada da história geológica, integrada à história da vida.

Assim, mais que a simples criação de uma disciplina, os conteúdos geológicos, com seus ramos físicos, químicos e biológicos, podem ser tratados numa organização interdisciplinar, agrupados, a critério das escolas, em projetos ou programas que superem a fragmentação atualmente verificada para a Geologia ou as Geociências como um todo. Isto deve ser feito sob a coordenação estrita de pessoal especificamente preparado. A experiência das últimas décadas mostra que os professores de Ciências, de Biologia e de Geografia preparados para esta tarefa são raros. Esses professores que têm apresentado os tópicos geológicos na escola básica já são das gerações que não tiveram em seus cursos a ministração da História Natural no sentido amplo. Mesmo porque, as Ciências da Terra evoluíram muito nos últimos 40 anos, e os professores ainda formados pelos cursos de História Natural (que já não atuam em sua maioria) não tiveram a formação dentro da visão moderna de Terra como um sistema e das teorias unificadoras dos fatos naturais. Os professores que ministram esses conteúdos geológicos são ou licenciados em Biologia, e não tiveram suficiente formação nos aspectos físicos e químicos dos processos geológicos, ou são formados em Geografia, e não têm a necessária óptica nem da Física e da Química, e nem da escala de tempo desde a origem do planeta, limitando a compreensão da real dimensão da dinâmica natural.

Assim, além da inserção de um conteúdo geocientífico íntegro no ensino, é urgente atualizar todo o professorado que lida com as Ciências Naturais e com a Geografia, para que não deixem de apresentar os tópicos geocientíficos quando for o caso, e que o façam com exatidão e com a visão moderna das Ciências do Sistema Terra.

\section{AGRADECIMENTOS}

A autora agradece ao Instituto de Geociências da USP pela oportunidade de participar de atividades ligadas aos cursos de Licenciatura e ao ensino de Geociências e aos revisores indicados pelo corpo consultivo da revista Geologia USP, que fizeram uma crítica construtiva do texto original, bem como ao Prof. Dr. Thomas Rich Fairchild, pelo Abstract. 


\section{REFERÊNCIAS BIBLIOGRÁFICAS}

ALLÈGRE, C. J. L'écume de la Terre. Paris: Fayard, 1983. $366 \mathrm{p}$.

BRASIL. Ministério da Educação. Secretaria de Educação Média e Tecnológica. Parâmetros curriculares nacionais: ensino médio. Brasília: Ministério da Educação, 1999. 364 p.

BRASIL. Lei n. 9394: diretrizes e bases da educação nacional, promulgada em 20/12/1996. Brasília: Editora do Brasil, 1996.

CAMPOS, D. A. O ensino das ciências da Terra. In: SIMPÓSIO A IMPORTÂNCIA DA CIÊNCIA PARA O DESENVOLVIMENTO NACIONAL, 1., 1997, São Paulo. Documentos... São Paulo: Academia Brasileira de Ciências, 1997. 1ª. Sessão: Educação, p. 39-46.

CARON, J. M.; GAUTHIER, A.; SCHAAF, A.; ULYSSE, J. e WOZNIAK, J. Comprendre et enseigner la Planète Terre. Paris: Ophrys, 1989. 271 p.

CHAPEL, A.; FIEUX, M.; JACQUES, G.; JACQUES, J. M.; LAVAL, K.; LEGRAND, M. e LE TREUT, H. Océans et atmosphère. Paris: Hachette Education, 1996. 160 p.

CRAIG, J. R.; VAUGHAN, D. J.; SKINNER, B. J. Resources of the earth. New Jersey: Prentice Hall, 1996. 472 p.

CHASSOT, A.; CAMPOS, H. Ciências da Terra e meioambiente: diálogos para (inter)ações no planeta. Porto Alegre: Unisinos, 2000. 284 p.

FRODEMAN, R. Geological reasoning: geology as an interpretive and historical science. GSA Bulletin, v. 107, n. 8, p. 960-968, 1995.

LEMOINE, M.; GRACIANSKY, P. C.; TRICART, P. De l'ocean à la chaîne de montagnes: tectonique des plaques dans les Alpes. Paris: Societé Géologique de France: Gordon \& Breach Science Publishers, 2000. 207 p. (Collection Géosciences).

MACKENZIE, F. T. Our changing planet. Upper Saddle River: Prentice Hall, 1998. 486 p.

POTAPOVA, M. S. Geology as an historical science of nature. In: INTERACTION of sciences in the study of the earth. Moscou: Progress Publishers, 1968. p. 117-126.

SEIBOLD, E. Offensive and defensive geology in our environment. Natural Resources and Development, Tubingen, v. 37, 1993. p. 99-109.

SIEMER, F.; BAYRHUBER, H.; HLAWATSCH, S. Earth science education in Germany: the project "System Earth" in upper secondary school. In: CONFERENCE ON GEOSCIENCE EDUCATION, 4., 2003, Calgary. Proceedings... Calgary: IGEO, 2003. p. 224.

WEINER, J. Os próximos cem anos. São Paulo: Campus, 1992.278p.

WILSON, E. O futuro da vida. São Paulo: Campus, 2002. $195 \mathrm{p}$. 